\title{
CHEMISTRY IN THE MOLECULAR ENVELOPE OF NGC 7027
}

\author{
P. COX ${ }^{1}$, R. BACHILLER ${ }^{2}$, P.J. HUGGINS ${ }^{3}$, A.OMONT ${ }^{4}$, S. GUILLOTEAU ${ }^{5}$ \\ ${ }^{1}$ Observatoire de Marseille, 2, pl. Leverrier, 13248 Marseille, France \\ ${ }^{2}$ Centro Astronomico de Yebes, Guadalajara, Spain \\ ${ }^{3}$ Department of Physics, New York University, NY 10003, USA \\ ${ }^{4}$ I.A.P., 98b, bd. Arago, 75014 Paris, France \\ ${ }^{5}$ IRAM, Grenoble, France
}

We report here a systematic study of the molecular content in the neutral envelope of NGC 7027. The measurements were done in September 1991 with the 30-meter IRAM telescope on Pico Veleta (Spain). The frequencies and transitions covered are given in Table 1. Long integrations were performed in each transitions toward the central position of NGC 7027, and for the strongest lines we obtained detailed maps. The results of the observation are given in Table 1 (in units of main beam temperature).

The main conclusions of this systematic search and mapping of molecules in the neutral envelope of NGC 7027 are:

1) the basic features of the chemistry in PNe described in Cox et al. (1992) - and references therein - also characterize the on-going chemistry in the envelope of NGC 7027 which is likely dominated by photodissociation, shocks, and ion-molecule reactions.

2) the detection of $\mathrm{N}_{2} \mathrm{H}^{+}(1-0)$ is the first detection of this ion in any stellar envelope.

3) From the higher and lower transitions of $\mathrm{HCN} \mathrm{HCO}^{+}$, and $\mathrm{CN}$, we estimate that the emitting regions have typical densities of a few $10^{5} \mathrm{~cm}^{-3}$.

A detailed analysis of the data will appear elsewhere.

\section{References}

Cox, P., Omont., A., Huggins, P.J., Bachiller, R., Forveille, T.: 1992, Astron. Astrophys. in press

Table 1: Observational results towards the central position of NG(: 7027

\begin{tabular}{|c|c|c|c|c|c|c|}
\hline Molecule & Line & $\begin{array}{c}\text { Frequency } \\
(\mathrm{MHz})\end{array}$ & $\begin{array}{c}\mathrm{T}_{m b} \text { (peak) } \\
\left(\mathrm{K}^{\prime}\right)\end{array}$ & $\begin{array}{r}\text { Area } \\
(\mathrm{K} \mathrm{km} / \mathrm{s})\end{array}$ & $\begin{array}{l}\text { r.m.s } \\
(\mathrm{mK})\end{array}$ & Comments \\
\hline $\mathrm{HCN}$ & $1-0$ & 88631.6 & 0.29 & 9.6 & 48 & mapped \\
\hline $\mathrm{HCN}$ & $3-2$ & 265880 & 0.58 & 10.4 & 76 & \\
\hline $\mathrm{HNC}$ & $1-0$ & 90663.6 & 0.014 & 0.58 & 6.1 & \\
\hline $\mathrm{HCO}^{+}$ & $1-0$ & 89188.6 & 1.12 & 21.6 & 16 & mapped \\
\hline $\mathrm{HCO}^{+}$ & $3-2$ & 267557 & 2.10 & 55.1 & 220 & \\
\hline \multirow[t]{2}{*}{$\mathrm{CN}^{\mathrm{a}}$} & $1-0$ & $113488-113520$ & 0.48 & 19.8 & 18 & mapped \\
\hline & & $113123-113191$ & 0.15 & 12.8 & 18 & mapped \\
\hline \multirow[t]{2}{*}{$\mathrm{CN}^{a}$} & $2-1$ & $226849-226913$ & 0.78 & 31.5 & 30 & mapped \\
\hline & & $226615-226697$ & 0.37 & 21.2 & 36 & mapped \\
\hline $\mathrm{N}_{2} \mathrm{H}^{+}$ & $1-0$ & 93174.0 & 0.06 & 1.57 & 10 & \\
\hline $\mathrm{C}_{2} \mathrm{H}$ & $1-0$ & 87316.9 & & $<0.5^{b}$ & 20 & \\
\hline $\mathrm{C}_{2} \mathrm{H}$ & $3-2$ & 262004.2 & & $<2.0^{b}$ & 80 & \\
\hline $\mathrm{C}_{3} \mathrm{~N}$ & $13-12$ & 128622.1 & & $<0.25^{b}$ & 10 & \\
\hline
\end{tabular}

\footnotetext{
a Sum of the hyperfine lines in high and low frequency components, respectively

${ }^{b}$ The upper limits on the area are derived from the noise level of the spectra (1 r.m.s) times $V_{\exp }$, where $V_{\exp }$ is $25 \mathrm{knns}^{-1}$
} 